\title{
JOURNAL.RU
}

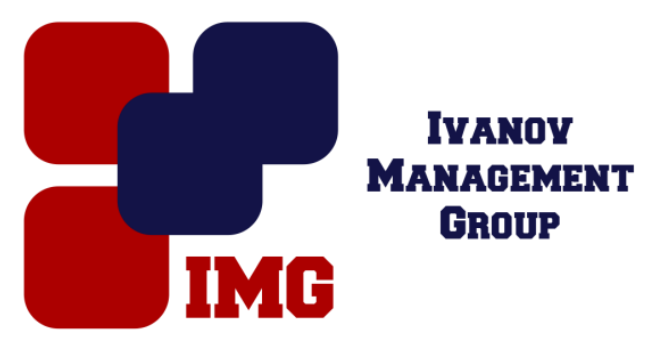

Гираев В.К. Дагестанский государственный технический университет Махачкала, Россия

doi: $10.18411 / 1 \mathrm{j}-31-05-2017-57$

idsp 000001:1j-31-05-2017-57

\section{Финансовые аспекты развития регионов}

\section{Аннотация}

В условиях санкционной политики западных стран и попыток международной изоляции России, роль и значение региональной политики развития возрастает многократно. При разработке стратегии регионального развития полезно учитывать опыт стран Евросоюза и принципы построения региональной политики. $\mathrm{B}$ статье сформулированы цели и задачи по стимулированию устойчивого экономического развития регионов России с учетом финансового и налогового потенциала.

Ключевые слова: регион, диспропорции развития, межбюджетные отношения, территориальное управление, региональное развитие, финансовый потенциал, налоговый потенциал, финансовая устойчивость, налоговая база, стратегия развития.

\section{Annotation}

In the context of the sanctions policy of the Western countries and the international attempts to isolate Russia, the role and importance of regional development policies increases many times. In the development of the regional development strategy is useful to consider the experience of the European Union and the principles of regional policy. The article stated goals and objectives to promote sustainable economic development of the regions of Russia, taking into account financial and tax potential. 
Key words: region, disparities of development, intergovernmental relations, territorial management, regional development, financial strength, tax potential, financial stability, the tax base, the development strategy.

Практика современного развития государств наглядно показала, что достижение социально-экономической сбалансированности развития регионов, выравнивание существенных территориальных, межрегиональных диспропорций не происходит спонтанно даже в “старых" странах рыночной экономики. Для устранения этих диспропорций и эффективного решения проблем обеспечения социальной и экономической территориальной справедливости необходимы действенная государственная поддержка, координация деятельности федерального центра и регионов по централизованному обеспечению гармонизации их интересов. На это и направлена правовая база, закрепленная в федеральном законе 29 декабря 2014 г. №473-Ф3 "О территориях опережающего социально-экономического развития в Российской Федерации".

В первую очередь, это касается региональной политики, направленной на устранение межрегиональных диспропорций с использованием механизмов межбюджетных отношений. Возникновение скрытых конфликтов интересов по вертикали (регион-федеральный центр) и по горизонтали (между регионамисубъектами федерации) неминуемо в условиях рынка: в частности, несовершенство межбюджетных отношений и соответствующее перераспределение финансовых ресурсов через федеральный бюджет вызывает осложнение отношений между регионами-“реципиентами” и регионами“донорами” и претензии последних к федеральной власти. Задача федерального центра в этих условиях заключается в нивелировании социально-экономических диспропорций через бюджетные и налоговые механизмы.

Региональная политика развития осуществляется в пределах единого экономического, финансового и правового пространства страны и потому предусматривает существование субъектно-объектных отношений между федеральным центром и регионами. В России такая политика в складывающихся условиях должна осуществляться на нескольких уровнях территориальной организации общества, среди которых основными должны быть три: макроуровень (объекты - экономические районы), мезоуровень (субъекты федерации) и микроуровень (административные районы). То, что экономические районы должны выступать объектами территориального управления, а значит - 
и региональной политики, подчеркивают в своих публикациях отечественные исследователи Г. Балакина[1], М. Дудин [2], В. Ланцов [3] и другие.

Для достижения этой цели реализация региональной политики развития должна быть направлена на решение ряда приоритетных задач. К важнейшим из них, по нашему мнению, относятся:

- обеспечение принципов единства экономического пространства и свободы перемещения товаров, капитала и рабочей силы по всей территории Российской Федерации;

- формирование и укрепление экономической основы для стимулирования самостоятельного экономического развития регионов путем четкого разграничения компетенции и ответственности между органами государственной власти, хозяйствующими субъектами и органами местного самоуправления по вопросам собственности, а также для принятия управленческих решений, в первую очередь, в сфере эксплуатации природных ресурсов, внешнеэкономической деятельности и т.д.;

- укрепление финансовой самостоятельности регионов;

- сглаживание объективно сложившихся межрегиональных отличий в уровнях экономического развития с использованием бюджетных и налоговых инструментов, в том числе через Федеральный фонд финансовой поддержки субъектов Российской Федерации и предоставление стимулирующих льгот по региональным и местным налогам;

- разработка государственной политики стимулирования развития территорий, имеющих большой научно-технический и производственный потенциал, способных стать центрами роста экономики с привлечением резидентов в соответствии с Федеральным законом от 29.12.2014 №473-Ф3 (ред. от 13.07.2015) "О территориях опережающего социально-экономического развития в Российской Федерации";

- поддержка регионов со сложной экологической обстановкой, демографическими и миграционными проблемами;

- использование конкурентных преимуществ территориального разделения труда, формирование хозяйственных комплексов и региональных рынков с учетом исторически сложившейся 
специализации и структуры экономики, реализация мероприятий по государственному регулированию транспортных тарифов и эффективной логистике.

В кардинально изменившихся условиях следует пересмотреть положения нормативно-правовых актов по вопросам регионального развития с целью активной реализации региональной политики в России, для чего считаем целесообразным воспользоваться опытом Евросоюза (ЕС), который в своей деятельности руководствуется следующими принципами [4, с. 99-100]:

- предоставление финансовой помощи регионам с четко выраженным отставанием в показателях экономического развития;

- проведение согласованной политики между центральным правительством, региональными и местными органами власти в процессе подготовки планов регионального развития, определения стратегических целей структурной модернизации;

- признание мультипликативной роли общегосударственных программ, которые направлены на стимулирование частных капиталовложений в слаборазвитые регионы, содействуя тем самым их развитию;

- решение конкретных задач на том уровне (местном, региональном, общегосударственном), который является наиболее эффективным;

- учет в общегосударственных программах стратегических целей региональной политики развития;

- тесная координация региональной политики с другими направлениями экономической политики страны.

Для разработки механизмов региональной политики, помимо политических инструментов и финансовых средств и методов, в странах ЕС с привлечением ученых и экспертов широко используются научнокоординационные мероприятия, которые объединяют проекты и решения экономических, социальных, экологических проблем отдельных стран (или групп стран), с активным обсуждением результатов их внедрения.

Эффективность и результативность региональной политики $\mathrm{EC}$ демонстрирует существенное повышение уровня социально-экономического развития в таких ранее депрессивных странах, как Ирландия, Португалия, Испания. Исходя из этого, можно предположить, что в связи с последующим расширением Евросоюза, в частности, за счет слабо или недостаточно развитых 
стран, таких как Польша, Литва, Румыния, региональная политика останется приоритетной составляющей стратегии эффективной перестройки ЕС.

Как видим из вышеприведенного, на всех уровнях региональная политика выступает как полиструктурная категория и охватывает основные сферы жизнедеятельности общества: экономическую, социальную, экологическую и т.д. В развитых странах приоритетными в такой политике являются социальные и экологические проблемы.

В условиях глобализации мирового хозяйства, обострения конкурентной борьбы за рынки сбыта, в том числе и природных ресурсов, для России особое значение приобретает региональная экономическая политика развития, направленная на стимулирование внутреннего спроса и расширение межрегиональных рынков. Главными целями такой политики выступают:

- обеспечение постепенного повышения уровня социальноэкономического развития регионов на основе эффективного территориального разделения труда и широкой межрегиональной кооперации;

- проведение экономических реформ с учетом экономических, естественных, социальных и других особенностей регионов;

- сбалансированное социально-экономическое и экологическое развитие регионов, повышение уровня благосостояния и обеспечение единых минимальных социальных стандартов и социальной защиты населения независимо от экономических возможностей регионов и др.

К долгосрочным целям региональной экономической политики, по нашему мнению, нужно отнести:

- широкое внедрение форм государственно-частного партнерства на региональном и межрегиональном уровне с широкой кооперацией, как в производственной сфере, так и в сфере сбыта готовой продукции;

- активное привлечение частного капитала и средств населения для усиления инвестиционной активности отечественных товаропроизводителей, в том числе и в рамках региональных программ импортозамещения; 
- расширение экономической независимости регионов в контексте общей концепции устойчивого развития страны и выравнивания уровней их экономического развития;

- обеспечение экономического роста регионов на основе модернизации инновационного комплекса;

- рациональное использование потенциала территории при опережающем наращивании его интеллектуальной, научнотехнической и информационной составляющих;

- формирование новых территориальных форм инновационной деятельности: технопарков и технополисов и т.д.

Достижение этих целей возможно при условии формирования и активного внедрения региональной финансовой политики как необходимой составляющей. В условиях жестких финансовых ограничений по стимулированию экономического развития важную роль играет политика поддержки регионов, которая в России сегодня неадекватна их потребностям. Сложившаяся практика оказания федеральным центром финансовой помощи реализует ущербную стратегию политики догоняющего, но не прорывного развития. Например, Постановление Правительства Российской Федерации №1444 от 23 декабря 2014 года «О первоочередных мерах по обеспечению опережающего развития Республики Дагестан» не есть масштабная стратегия, а носит декларативный и рекомендательный характер.

Примечание: В мировой практике для стимулирования опережающего развития создаются особые экономические зоны (ОЭЗ), в рамках отдельных законов. Для резидентов этих зон предусмотрены налоговые и таможенные преференции, инвестиционные льготы, упрощченные процедуры регистрации собственности, земельных отночений и ведения предпринимательской деятельности. Создание ОЭЗ привязана $к$ решению главных задач стимулирование предпринимательской активности, опережающий рост валового регионального продукта, обеспечение населения занятостью, решение сочиальных задач.

Указанное Постановление не предусматривает создание на территории Республики Дагестан ОЭЗ, специальных таможенных режимов, их территориальное разграничение, особые условия для резидентов, не указаны виды их деятельности, не определены минимальные объемы капитальных вложений. 
Более того, не видно никакой корреляции между указанным Постановлением и базовым Федеральнылм законом от 29.12.2014 №473-Ф3 (ред. от 13.07.2015) «О территориях опережсаюего сочиально-экономического развития в Российской Федерации». «Оживить» Постановление возможно только при дополнении его соответствующцми планами и программами в увязке с основньми положениями указанного федерального закона. В этом случае, высока вероятность превращчения декларативного Постановления в "дорожную карту" для республики по выводу ее из депрессивного состояния, живущего за счет трансфертов и дотаций из федерального цуентра.

Масштабы финансовой помощи федерального центра конкретным регионам очень разные. Именно в их дифференциации и проявляется во многих случаях региональная финансовая политика. Считаем, что в России такая политика малоэффективна потому, что не всегда “адресно” оправдана. К тому же, поддержка регионов на федеральном уровне направлена в первую очередь не на стимулирование их экономического развития, а на пассивную финансовую помощь и сохранение политической управляемости.

Для решения вопросов регионального развития в современных условиях, по нашему мнению, следует акцентировать внимание не на определении потребностей в финансовой помощи регионам и ее распределении, а на анализе полного учета финансовых ресурсов регионов, объективной оценке возможностей субъектов федерации в мобилизации финансового потенциала, как на уровне страны, так и ее регионов.

Необходимо отметить, что в научной литературе нет четкого разграничения между понятиями “налоговый” и “финансовый” потенциалы, что связано с типом государственного устройства, организацией финансовой и налоговой систем вкупе с действующей в стране системой межбюджетных отношений. Да и в зарубежных странах с развитыми формами моделей бюджетного федерализма эти два понятия зачастую отождествляются [5, с. 3].

Особенности развития экономики России на современном этапе требуют четкого разграничения их содержания.

Под финансовым потенциалом мы понимаем совокупность всех финансовых ресурсов, которые сосредоточены и могут быть вовлечены в хозяйственную деятельность в конкретном субъекте федерации.

В зависимости от характера собственности в состав финансового потенциала региона входят [6, с. 5]: 
1) финансовый потенциал юридических лиц региона с рыночной оценкой стоимости их активов (или пассивов);

2) финансовый потенциал населения региона, который оценивается на основе рыночной стоимости имущества в домашних хозяйствах;

3) собственный финансовый потенциал государства, оценка которого формируется на основе рыночной стоимости активов государственных предприятий и предприятий других форм собственности, а также стоимости природных ресурсов, которыми владеет регион.

Налоговый потенциал - важная составляющая финансового потенциала региона. Он включает в себя лишь ту часть финансовых ресурсов, которая формирует налоговые доходы бюджета и служит для оценки налоговой базы региона. В состав финансового потенциала могут входить также финансовые ресурсы, которые вообще не являются объектами налогообложения или же подпадают под него частично (доходы от собственности и операций с ней, ссуды для финансирования определенных программ или на покрытие бюджетного дефицита и т.д.) [5].

Учитывая тот факт, что налоговый потенциал является первоосновой для анализа финансового потенциала регионов, региональная финансовая политика должна быть направлена на реализацию взвешенной, адекватной интересам страны и регионов налоговой политики как важной ее составляющей, поскольку существующая налоговая политика не способствует заинтересованности регионов в расширении налоговой базы. Для решения этой важной проблемы необходимо обосновать общую стратегию развития налоговой политики, направленную на усиление ее регулирующих и стимулирующих функций на основе разграничения между федеральным центром и регионами обязательств и полномочий по реализации механизмов налогообложения.

Эффективная региональная налоговая политика должна обеспечить рациональное распределение налоговой нагрузки между регионами, учитывая их налогоспособность, уровень экономического развития и налоговый потенциал, а также способствовать сохранению и росту финансовой устойчивости.

Финансовая устойчивость составляет критически важную характеристику макроэкономической ситуации и финансового пространства государства, отражает состояние ее финансовой системы в регионально-территориальном измерении со всей сложностью еe межрегиональных структурнофункциональных отношений. В связи с этим финансовая устойчивость должна обеспечиваться на всех уровнях: страны, региона, предприятий и т.д. 
В соответствии с этими уровнями существенно меняется содержание и механизм обеспечения финансовой устойчивости. На уровне региона, по нашему мнению, финансовая устойчивость отражает не столько соотношение собственных и привлеченных финансовых ресурсов, сколько уровень его финансового обеспечения для выполнения всех функций по достижению эффективного поступательного регионального развития. При таком понимании финансовая устойчивость в значительной мере обусловлена степенью финансового обеспечения воспроизводственных процессов, прежде всего, накопление собственного капитала, воспроизводство населения и квалифицированной рабочей силы, расширение объемов производства товаров, работ и услуг, наращивание национального богатства в целом.

Следовательно, общепринятое толкование научной категории “финансовая устойчивость" как соотношение собственных и привлеченных финансовых ресурсов есть, по нашему мнению, лишь один из вариантов отражения содержания этой сложной и многогранной категории. Считаем, что в расширенном толковании финансовая устойчивость на уровне региона отражает уровень его экономического роста и обеспечения финансовыми ресурсами для реализации общественно необходимых потребностей.

Таким образом, в условиях дефицита бюджетных ресурсов и высоких рисков, с которыми сталкивается Россия, назрела необходимость в коренном пересмотре стратегий регионального развития. Центр тяжести должен быть смещен на стимулирование внутреннего спроса и максимальный учет региональных финансовых и налоговых ресурсов, максимальное расширение программ импортозамещения. Такой подход позволит выстроить эффективную стратегию социально-экономического развития субъектов Российской Федерации, обеспечит их финансовую устойчивость и создаст прочную основу противодействия глобальным вызовам, с которыми сталкиваются, прежде всего, регионы. 
1. Балакина Г.Ф. Особенности формирования стратегии социально-экономического развития региона в условиях модернизации // Регион: экономика и социология. -2014.№ 3. C. 113-127.

2. Дудин М.Н.Обеспечение устойчивости экономического роста на региональном уровне в условиях инновационного развития // Региональная экономика: теория и практика. 2015. -№14(389). -C. 2-15.

3. Ланцов В.А., Бабкина Л.Н., Песецкая Е.В. Потенциал территории: экономические, социальные и экологические аспекты: монография. -СПб.: -URSS, -1994. -232 с.

4. Коровкин В. Европейская интеграция и региональная политика // Мировая экономика и международные отношения. - 1997. - № 4. - С. 99-100.

5. Коломиец А.Л., Мельник А.Д. О понятиях налогового и финансового потенциалов регионов // Налоговый вестник. - 2000. - № 1. - С. 3-5.

6. Коломиец А.Л., Новикова А.И. О соотношении финансового и налогового потенциалов в региональном разрезе // Налоговый вестник. - 2000. - № 3. - С. 5-8. 